\title{
Light and health: a century after the therapeutic use of UV light and vitamin D, hormones advanced medical care
}

\author{
Josef Köhrle (101, Martina Rauner ${ }^{2,3}$ and Susan A Lanham-New ${ }^{4}$ \\ ${ }^{1}$ Charité - Universitätsmedizin Berlin, corporate member of Freie Universität Berlin and Humboldt-Universität zu Berlin, Institut für Experimentelle \\ Endokrinologie, Berlin, Germany \\ ${ }^{2}$ Department of Medicine III, Universitätsklinikum Dresden, Technische Universität Dresden, Dresden, Germany \\ ${ }^{3}$ Center for Healthy Aging, Universitätsklinikum Dresden, Technische Universität Dresden, Dresden, Germany \\ ${ }^{4}$ Department of Nutritional Sciences, School of Biosciences and Medicine, Faculty of Health and Medical Sciences, University of Surrey, Guildford, UK
}

\section{Correspondence should be addressed to J Köhrle: josef.koehrle@charite.de}

This paper forms part of a special series on 100 Years of Vitamin D. The guest editors for this section were Josef Köhrle, Susan Lanham-New and Martina Rauner

Contemporary medicine focuses its therapeutic approaches on the personalized targeting of key molecular elements with respect to mechanism-based pathways, or molecules involved in pathophysiologically relevant processes that are causally related (or indeed associated with various diseases). Classical chemicals-based pharmaceuticals, recombinant proteins, monoclonal antibodies and biologicals, and (very recently) mRNA-based vaccines, have successfully expanded the therapeutic spectrum, whilst efficient preventive approaches have proved challenging.

More than a century ago, a prevailing condition that adversely affected child development and was termed the 'English disease', but which was widespread over most industrialized regions and major cities in the northern hemisphere, received high attention. Rickets had been associated with poor nutrition, lack of sun exposure, poor life conditions and low socioeconomic status. First tentative nutritional (cod oil) and therapeutic (sunlight exposure) measures achieved initial and significant successes. However, families living on low incomes could not afford to prevent this disease by exposing their offspring to fresh air and sun during the summer months in southern European regions.

After a first reported communication on the light treatment of rickets in 1904 (1) and a suggestion that sunlight deficiency caused rickets (2), rational medical prevention and therapy were 'enlightened' by a series of reports published by Huldschinsky between 1919 and 1921 (3). He demonstrated that exposure to 'artificial sunlamps', i.e. UV light, generated by recently developed mercury quartz lamps, healed and prevented rickets in children after repeated exposure. The role of calcium deficiency, the beneficial effects of cod-liver oil and sun exposure were already known, but insufficient to understand or prevent the underlying pathophysiology. Mellanby established an experimental animal model in dogs that mimicked human rickets (4). McCollum et al. identified a lipidsoluble agent, distinct from the already known vitamin A, which they called vitamin $\mathrm{D}$, as a nutritional antirachitic component which promoted calcium deposition in bones (5). In a series of systematic nutritional animal experiments, the physicians Hess and Weinstock and the biochemist Steenbock clearly demonstrated that not only the UV exposure of white rats, but also UV irradiation of their daily chow could prevent rickets $(6,7)$. Since then, the beneficial effects of 'vitasterin', generated from cholesterol by irradiation of lipid-containing food, were tested in various experimental approaches.

Vitamin D2 (ergocalciferol, calcidiol) was isolated from a mixture of UV-irradiated ergosterol by Askew et al. in 1928 (8). Windaus and colleagues eventually characterized 7-dehydrocholesterol and vitamin D3 as the natural vitamin $\mathrm{D}$ formed in the skin by UV-B irradiation of its precursor 7-dehydrocholesterol between 1935 and 1937 $(9,10)$. The sterol expert Windaus had already been decorated by the Nobel committee for his research on the composition of sterols and their connection to vitamins in 1928. The formal mass spectrometry confirmation of this
This work is licensed under a Creative Commons Attribution-NonCommercial 4.0 International License. ded from Bioscientifica.com at 04/26/2023 01:50:08PM 
UV-dependent non-enzymatic activation reaction in the skin was not, however, provided until 1978 by Esvelt et al. (11). Non-enzymatic light-induced biological reactions obviously occur in the retina for the visual process by isomerization of cis- to trans-retinal, and blue light photon activation (480 $\mathrm{nm}$ ) of the melanopsin receptor in retinal ganglion cells instructs the circadian clock of the suprachiasmatic nucleus and suppresses epiphysial melatonin production, as well as melanophore activation in the skin.

This special series on 100 Years of Vitamin D, published in Endocrine Connections, addresses recent developments and global epidemiological, diagnostic and therapeutic medical issues around vitamin D hormone(s) with an introductory historical perspective on biological functions and measurement of the 'sun hormone' vitamin D. Patient-tailored therapeutic measures require adequate diagnostics and monitoring of the systemic concentrations of the 25OHD hormone precursor, still the best parameter reflecting a patient's vitamin D hormone status, and the (local) changes in its active hormone form calcitriol. This will remain a major analytical challenge, considering various nutritional and supplemental interferences of closely related vitamin D metabolites in commercially available immunoassays, which are only partially harmonized and calibrated to validated reference materials. Notoriously complex vitamin D measurements, including mass spectrometry-based analytics, are probably one of the most frequently used hormone assays worldwide.

Interpretation of tissue-specific vitamin $\mathrm{D}$ metabolism remains a major challenge, with respect to the pre-receptor control of ligand availability for intracellular vitamin D receptors, which are modulated by intracellular activation and inactivation of vitamin D precursors, and the hormonally active calcitriol. The vitamin D metabolome, its clinical impact, the key enzymes involved in vitamin D metabolism and aspects of genetic background are still under investigation. Controversies still exist regarding vitamin D requirements in normal health and disease under the epidemiological, preventive and health economics aspects related to different endpoints, biomarkers or surrogate outcome parameters. Global differences in vitamin D status and dietary intake have been identified, and remain extremely challenging in both developed and developing countries as reviewed by Cashman (12). Webb and coworkers evaluated available data for dose-response relationships for changes in $25 \mathrm{OHD}$ serum concentrations on whole-body exposure of the human fur-less skin to repeated sub-erythemal doses of UV radiation, revealing large interpersonal variations in response to UV exposure with skin type as a determinant of response to UV radiation (13), which makes the optimum sunlight exposure level for maximum vitamin D effects difficult to quantify. One of the main targets of vitamin D hormones is the musculoskeletal system in relation to vitamin $\mathrm{D}$ metabolism and action, and this has raised ongoing controversies with respect to prevention and treatment of age- and gender-dependent diseases and health protection. Multiple interconnections with vitamin D have been revealed for auto-immune diseases. Some of these topics are expected to be the subject of further articles in this special series. Vitamin D interactions and the implications for the management of the current COVID-19 pandemic waves have become a very hot topic, with a focus on acute respiratory tract infections. An initial analysis of vitamin D concentration, BMI, ethnicity and SARS-CoV-2/COVID-19 of UK Biobank cohort cases and controls is expected to shed some light on these complex interrelations.

Several original research papers may complement this special series and deal with vitamin $\mathrm{D}$ deficiency in relation to male and female fertility, vitamin D-dependent course and outcome of cardio-metabolic diseases, and the impact of vitamin D status on autoimmune diseases. Public health issues in relation to dietary calcium and vitamin $\mathrm{D}$ intake and socioeconomic status remain a burning issue a century after their detection and scientific documentation. The area remains one of intense debate; scientific research in this field must continue apace to ensure that the benefits

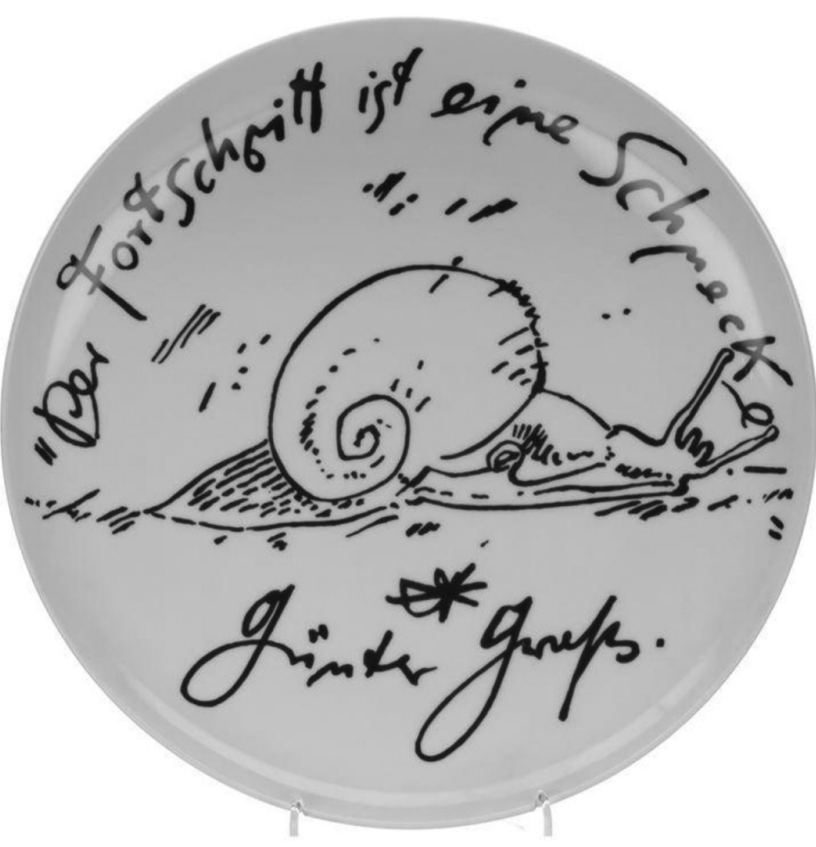

Figure 1

Progress is a snail ('Der Fortschritt ist eine Schnecke'). Quotation by the Nobel Award winner Günter Grass decorating a collector series of table plates manufactured as part of 'Rosenthal Serie Künstlerteller'.

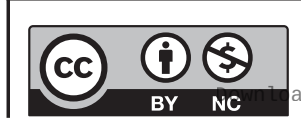

This work is licensed under a Creative Commons Attribution-NonCommercial 4.0 International License. ded from Bioscientifica.com at 04/26/2023 01:50:08PM 
(and limitations) of vitamin D for optimum health can be fully elucidated. Even if the progress of innovation is presented as a snail by Günter Grass in Fig. 1, hopefully, vitamin D research will outpace the snail.

\section{Declaration of interest}

The authors declare that there is no conflict of interest that could be perceived as prejudicing the impartiality of this editorial.

\section{Funding}

This work did not receive any specific grant from any funding agency in the public, commercial or not-for-profit sector.

\section{References}

1 Buchholz E. Ueber Lichtbehandlung der Rachitis und anderer Kinderkrankheiten, p. 116. Breslau, Germany: Verhandlungen der Gesellschaft für Kinderheilkunde in der Abteilung für Kinderheilkunde der 76. Versammlung der Gesellschaft Deutscher Naturforscher und Aerzte in Breslau, 1904.

2 Raczynski J. Recherches Expérimentales sur le Manque d'Action au Soleil Comme Cause du Rachitisme, pp. 308-309. Paris: C. R. Assoc. Internat. Pediatrie, 1912/13.

3 Huldschinski K. Heilung von Rachitis durch künstliche Höhensonne. Deutsche Medizinische Wochenschrift 191945 712-713. (https://doi. org/10.1055/s-0028-1137830)
4 Mellanby E. An experimental investigation on rickets. Lancet 19191 407-412.

5 McCollum EV, Simmonds N, Becker JE \& Shipley PG. An experimental demonstration of the existence of a vitamin which promotes calcium deposition. Journal of Biological Chemistry 192253 293-312. (https:// doi.org/10.1016/S0021-9258(18)85783-0)

6 Steenbock $\mathrm{H}$. The induction of growth promoting and calcifying properties in a ration by exposure to light. Science $192460224-225$. (https://doi.org/10.1126/science.60.1549.224)

7 Hess AF \& Weinstock M. Antirachitic properties imparted to lettuce and to growing wheat by ultraviolet irradiation. Experimental Biology and Medicine 192422 5-6. (https://doi.org/10.3181/00379727-22-3)

8 Askew FA, Bourdillon RB, Bruce HM, Jenkins RGC \& Webster TA. The distillation of vitamin D. Proceedings of the Royal Society of London Series A 1931 B107 76-90. (https://doi.org/10.1098/rspb.1930.0054)

9 Windaus A, Lettre H \& Schenck F. 7-Dehydrocholesterol. Annali di Chimica $1935 \mathbf{5 2 0}$ 98-106.

10 Windaus A \& Bock F. Über das Provitamin aus dem Sterin der Schweineschwarte. Zeitschrift für Physiologische Chemie 1937245 168-170. (https://doi.org/10.1515/bchm2.1936.245.3-4.168)

11 Esvelt RP, Schnoes HK \& DeLuca HF. Vitamin D3 from rat skins irradiated in vitro with ultraviolet light. Archives of Biochemistry and Biophysics 1978188 282-286. (https://doi.org/10.1016/s00039861(78)80010-1)

12 Cashman KD. 100 YEARS OF VITAMIN D: Global differences in vitamin D status and dietary intake: a review of the data. Endocrine Connections 202211 e210282. (https://doi.org/10.1530/EC-21-0282)

13 Webb AR, Alghamdi R, Kift R \& Rhodes LE. 100 YEARS OF VITAMIN D: Dose-response for change in 25-hydroxyvitamin D after UV exposure: outcome of a systematic review. Endocrine Connections 202110 R248-R266. (https://doi.org/10.1530/EC-21-0308)

Received in final form 8 December 2021

Accepted 8 December 2021

Accepted Manuscript published online 9 December 2021
This work is licensed under a Creative Commons Attribution-NonCommercial 4.0 International License. ded from Bioscientifica.com at 04/26/2023 01:50:08PM 